\title{
Protective effects of miR-25 against hypoxia/reoxygenation-induced fibrosis and apoptosis of $\mathrm{H9c2}$ cells
}

\author{
QIFANG LIU $^{1}$, YONGJIN WANG ${ }^{2}$, TIANLUN YANG ${ }^{1}$ and WU WEI ${ }^{2}$ \\ ${ }^{1}$ Department of Cardiology, Xiangya Hospital, Central South University, Changsha, Hunan 410078; \\ ${ }^{2}$ Department of Cardiology, Heping Hospital, Changzhi Medical College, Changzhi, Shanxi 046000, P.R. China
}

Received December 9, 2015; Accepted July 21, 2016

DOI: $10.3892 /$ ijmm.2016.2702

\begin{abstract}
It has been previously demonstrated that microRNA (miR)-25 plays critical roles in collagen deposition. Ischemia/reperfusion injury to the myocardium results in fibrosis and collagen deposition. However, whether miR-25 is involved in the development of hypoxia/reoxygenation (H/R)-induced fibrosis in cardiomyocytes or not remains largely unknown. For this purpose, in the present study, cardiomyocyte $\mathrm{H} 9 \mathrm{c} 2$ cells were subjected to H/R. The techniques of flow cytometry, western blot analysis and RT-qPCR were used and we observed increases in the cell apoptosis rate and fibrosis as well as blocking of the cell cycle in the G1 phase. Moreover, the expression of miR-25 was downregulated after H/R and high-mobility group box 1 (HMGB1) expression was increased. We also found that the overexpression of miR-25 under conditions of $\mathrm{H} / \mathrm{R}$ inhibited fibrosis and cell apoptosis as well as reversing the cell cycle blocking. Additionally, the targeting of HMGB1 by miR-25 was confirmed by a dual-luciferase reporter gene assay. Moreover, the effects of miR-25 were further enhanced by a transforming growth factor- $\beta 1$ (TGF- $\beta 1$ )/Smad3 inhibitor, SB431542, as fibrosis was reduced and apoptosis was suppressed. In conclusion, the protective effects of miR-25 against H/R-induced fibrosis and apoptosis H9c2 cells were due to direct targeting of HMGB1 through the downregulation of the TGF- $\beta 1 / \mathrm{Smad} 3$ signaling pathway.
\end{abstract}

\section{Introduction}

Ischemia/reperfusion (I/R) injury to the myocardium, kidney and lungs results in fibrosis, which is mainly mediated by inflammation, the transdifferentiation of fibroblasts to fibroblasts and collagen deposition (1-3). One of the molecular pathways involved is the epithelial to mesenchymal transition (EMT) (4).

Correspondence to: Professor Yongjin Wang, Department of Cardiology, Heping Hospital, Changzhi Medical College, 161 Jiefang East Road, Changzhi, Shanxi 046000, P.R. China

E-mail: yongjinwang@sohu.com

Key words: high-mobility group box 1, miR-25, apoptosis, fibrosis, hypoxia/reoxygenation, transforming growth factor- $\beta 1 / \mathrm{Smad} 3$
High-mobility group box 1 (HMGB1), a non-chromosomal nuclear protein that regulates gene transcription and maintains the nucleosome structure (5), has been identified as an inflammatory factor that regulates the EMT process (6). Additionally, HMGB1 has been proved to be associated with I/R injury. A previous study has shown that cardiac HMGB1 expression is upregulated following I/R injury of the heart, and the inhibition of HMGB1 significantly reduced tissue inflammation, injury and fibrosis in addition to improving cardiac performance (7). Taken together, these findings suggest that HMGB1 is a novel target for suppressing the inflammatory process and reducing I/R injury.

MicroRNAs (miRNAs or miRs), a type of small, non-coding RNA that regulate protein expression (8), are also thought to play crucial roles in the development of fibrosis. For example, miR-21 simultaneously regulated ERK1 signaling in hepatic stellate cell (HSC) activation and hepatocyte EMT in hepatic fibrosis (9). miR-21 promoted fibrogenic EMT of epicardial mesothelial cells which involved programmed cell death 4 and sprouty-1 (10). Furthermore, miRNAs have been implicated in the regulation of HMGB1. For example, miR-129-2 directly targeted HMGB1 and inhibited its expression in glioma cells (11). Lu et al demonstrated that miR-181b inhibited the expression of HMGB1 and Mcl-1 by directly binding to their 3'-untranslated regions (3'-UTRs) (12). Furthermore, overexpressed miR-21 targeted the 3'-UTR of HMGB1 and inhibited HMGB1-induced autophagy (13).

miR-25 is a member of the miR-106b 25 cluster that is associated with EMT and potentially exerts effects on kidney fibrosis (14). Divakaran et al demonstrated that miR-25 reduced collagen deposition during cardiac fibrosis (15). However, whether miR-25 plays a role in hypoxia/reoxygenation (H/R)-induced fibrosis and apoptosis, and whether HMGB1 is a target of miR-25, remains largely unknown.

In this study, we examined the effects of miR-25 on H/R-induced fibrosis and the apoptosis of cardiomyocyte $\mathrm{H} 9 \mathrm{c} 2$ cells as well as the precise mechanisms responsible for these effects. Firstly, we detected the expression of miR-25 and HMGB1 in H/R-exposed H9c2 cells. Cell cycle analysis as well as measurement of the apoptotic rate was performed in the H/R-exposed cells. Furthermore, we established miR-25-overexpressing and miR-25-silenced cell lines in order to examine the effect of miR-25 on fibrosis and apoptosis. We then confirmed that miR-25 directly targeted HMGB1 and downregulated HMGB1 expression. For signaling pathway 
analysis, transforming growth factor- $\beta 1$ (TGF- $\beta 1) / S m a d 3$ and ERK1/2 were analyzed following HMGB1 knockdown. Moreover, an inhibitor of the TGF- $\beta 1 / \mathrm{Smad} 3$ pathway was used to evaluate the effects of miR-25. Taken together, the findings of the present study may provide novel insights into the pathogenesis of fibrosis, particularly with regard to H/R-related heart failure.

\section{Materials and methods}

Cell culture. H9c2 cells were purchased from Auragene (Changsha, China). This cell line was recently authenticated and tested for contamination. The cells were cultured in Dulbecco's modified Eagle's medium (DMEM; HyClone, Logan, UT, USA) supplemented with $10 \%$ fetal calf serum (Gibco, Gaithersburg, MD, USA). For H/R exposure, H9c2 cells were cultured under hypoxic conditions for $6,12,24$ or $36 \mathrm{~h}$, followed by reoxygenation for $1 \mathrm{~h}$. The cells were then harvested for use in subsequent experiments.

Flow cytometric analysis. An Annexin V apoptosis detection kit (Life Technologies, Grand Island, NY, USA) was used for apoptosis detection. Following exposure to H/R, H9c2 cells were collected, and washed twice with cold phosphate-buffered saline (PBS) and $500 \mu 1$ binding buffer was used to resuspend the cells. Annexin V-FITC (5 $\mu \mathrm{l})$ and propidium iodide (PI) $(5 \mu \mathrm{l})$ were added to the solution and mixed well. Following a 15-min incubation period at room temperature in the dark, the cells were analyzed using a flow cytometer (BD Biosciences, San Jose, CA, USA).

For cell cycle analysis, following exposure to H/R, the H9c2 cells were collected, and washed twice with cold PBS and $500 \mu 1$ PBS was used to resuspend the cells. The cells were fixed in 70\% ethanol overnight, centrifuged and washed with PBS three times. Finally, $0.2 \mathrm{mg}$ RNase A and $1 \mathrm{ml} \mathrm{PI} /$ Triton X-100 solution were used to resuspend the cells for $15 \mathrm{~min}$. The cells were analyzed using a flow cytometer (BD Biosciences).

Reverse transcription-quantitative polymerase chain reaction $(R T-q P C R)$. Total RNA was extracted from H9c2 cells using TRIzol reagent (Life Technologies, Shanghai, China) according to the manufacturer's instructions. cDNA was synthesized using the TaqMan MicroRNA Reverse Transcription kit (Applied Biosystems, Foster City, CA, USA). qPCR was performed using a quantitative fluorescence PCR instrument (ABI 7500 Thermocycler; Life Technologies) and SYBR-Green Universal PCR Master Mix (Bio-Rad, Hercules, CA, USA). The following oligonucleotide sequences of the primer sets were used: miR-25 (HmiR0109); U6 (HmiRQP9001) (both from Fulengen, Guangzhou, China); HMGB1 sense, GGA GAG TAA TGT TAC AGA GCG G and antisense, AGG ATC TCC TTT GCC CAT GT; collagen I sense, ATC AGC CCA AAC CCC AAG GAG A and antisense, CGC AGG AAG GTC AGC TGG ATA G; collagen III sense, TGA TGG GAT CCA ATG AGG GAG A and antisense, GAG TCT CAT GGC CTT GCG TGT TT; matrix metallopeptidase 2 (MMP2) sense, TGA TGG CAT CGC TCA GAT CC and antisense, GGC CTC GTA TAC CGC ATC AA; TIMP metallopeptidase inhibitor 2 (TIMP2) sense, TGT GAC TTC ATC GTG CCC TG and antisense, ATG TAG CAC GGG
ATC ATG GG; $\beta$-actin sense, AGG GGC CGG ACT CGT CAT ACT and antisense, GGC GGC ACC ACC ATG TAC CCT). qPCR was performed in a total volume of $20 \mu \mathrm{l}$, including $10 \mu \mathrm{l}$ of $2 \mathrm{X}$ SYBR-Green qPCR mix, $1 \mu \mathrm{l}$ of each forward and reverse primer $(10 \mu \mathrm{mol} / \mathrm{l}), 1 \mu \mathrm{l}$ of each cDNA sample and $7 \mu 1 \mathrm{H}_{2} \mathrm{O}$. Amplifications were performed in triplicate in 96-well microtiter plates. The following thermal cycling conditions were used: $95^{\circ} \mathrm{C}$ for $3 \mathrm{~min}, 35$ cycles of $95^{\circ} \mathrm{C}$ for $10 \mathrm{sec}$, and $58^{\circ} \mathrm{C}$ for $30 \mathrm{sec}$, finally followed by $95^{\circ} \mathrm{C}$ for $12 \mathrm{sec}$, and $58^{\circ} \mathrm{C}$ for $50 \mathrm{sec}$.

Western blot analysis. Whole-cell lysates were harvested and washed with PBS, and then lysed in a buffer containing $150 \mathrm{mM} \mathrm{NaCl}, 1 \mathrm{mM}$ PMSF, $\mathrm{NaVO}_{4}$, aprotinin and leupeptin as protease inhibitors, in $50 \mathrm{mM}$ Tris- $\mathrm{HCl} \mathrm{pH} 8.0,0.2 \%$ sodium dodecyl sulfate (SDS) and 1\% NP-40. Thirty micrograms of protein per sample was resolved on an SDS-polyacrylamide gel with subsequent transfer blotting. The membranes were incubated at $4^{\circ} \mathrm{C}$ with a primary antibody overnight [HMGB1, (ab79823; Abcam, Cambridge, UK); TIMP2 (sc-6835) and MMP2 (sc-10736) (both from Santa Cruz Biotechnology, Inc., Santa Cruz, CA, USA); collagen I (ab34710) and collagen III (ab7778) (both from Abcam); TGF- $\beta 1$ (YT4632, Immunoway, Newark, DE, USA); ERK1/2 (ab17942; Abcam); phosphorylated (p-)ERK1/2 (sc-16982; Santa Cruz Biotechnology, Inc.); Smad3 (ab40854; Abcam); p-Smad3 (sc-130218; Santa Cruz Biotechnology, Inc.); Bcl-2 (ab117115) and cleaved caspase-3, ab2302 (both from Abcam)]. After washing, the membranes were incubated with the corresponding secondary antibody [111-035-003; 111-035-008 (Jackson ImmunoResearch Laboratories, West Grove, PA, USA)] for $1 \mathrm{~h}$ at room temperature, followed by chemiluminescence for visualization. For the control group, the membrane was stripped and reprobed using an actin antibody after probing each membrane with the primary antibody.

Transfection. H9c2 cells were cultured as described above prior to transfection. To knockdown the endogenous expression of miR-25, an miR-25 inhibitor (a recombinant lentivirus of Lv-anti-miR-25) was used and to upregulate miR-25, a recombinant lentivirus of Lv-miR-25 (both from GeneChem, Shanghai, China) was used. As a negative control, an miR inhibitor or overexpression control (lentivirus of Lv-con and Lv-anti-con; GeneChem) was transfected into the H9c2 cells. Then, miR-25 gain/loss models and their controls with the neomycin resistance gene were successfully isolated using G418 (10131-027; Invitrogen Life Technologies, Carlsbad, CA, USA). The stably transfected cells were subjected to hypoxic conditions for $24 \mathrm{~h}$, followed by reoxygenation for $1 \mathrm{~h}$. The cells were then harvested for evaluation by western blot analysis, RT-qPCR and flow cytometry.

HMGB1-shRNA and shRNA control were used to regulate the expression of HMGB1. All the plasmids were purchased from Auragene. Transfection was performed using Lipofectamine ${ }^{\mathrm{TM}} 2000$ (Invitrogen) according to the manufacturer's instructions. Briefly, 100 pmol of mimics was diluted in $250 \mu 1$ DMEM, which was then mixed with $10 \mu \mathrm{l}$ Lipofectamine 2000 (diluted in $250 \mu \mathrm{l}$ serum-free medium). Following incubation at $37^{\circ} \mathrm{C}$ for $4 \mathrm{~h}$, the medium was replaced with complete medium and incubated for a further $24 \mathrm{~h}$. The cells were then collected for H/R exposure. 
miR-25-overexpressing cells were incubated with or without SB431542 (10 $\mu \mathrm{M})$ (S1067; Selleck Chemicals, Houston, TX, USA) for $24 \mathrm{~h}$, and then subjected to H/R.

Prediction of miRNA-25 targets. The miRNA databases and target prediction tool, microRNA.org-Targets and Expression, was used to identify potential miR-25 targets.

Dual-luciferase reporter gene assay. A Dual-Luciferase Reporter Gene assay kit (E1910; Promega, Madison, WI, USA) was used in the study. For the luciferase reporter experiments, a 3'-UTR segment of the HMGB1 gene (accession no.NM_002128.5) was amplified by PCR from human genomic DNA using primers that included an XhoI and NotI tails on the $5^{\prime}$ and $3^{\prime}$ strands, respectively. PCR products were recombined with psi-CHECK2. The H9c2 cells were then transfected with the firefly luciferase HMGB1-3'UTR-psi-CHECK2, combined with miR-25 mimics (HmiR-AN0351), miR-25 inhibitor (HmiR-AN0351-SN-10), miRNA NC mimics (CmiR-AN0001), and miRNA NC inhibitor (CmiR-AN0001-SN) (all from Fulengen), respectively. Twenty-four hours after transfection, the cells were lysed with a $1 \mathrm{X}$ passive lysis buffer and the activity of both Renilla and firefly luciferase was assayed using the dual-luciferase reporter assay system (Promega) according to the manufacturer's instructions.

Statistical analysis. All experiments were repeated three times. All data are presented as the means $\pm \mathrm{SD}$. Comparisons between groups were performed by one-way analysis of variance (ANOVA) using SPSS 17.0 software (SPSS Inc., Chicago, IL, USA) and Prism 5.0 software (GraphPad Software Inc., San Diego, CA, USA). A P-value $<0.05$ was considered to indicate a statistically significant difference.

\section{Results}

$H / R$ upregulates HMGB1 expression and downregulates miR-25 expression as well as increasing fibrosis and enhancin the apoptosis of $\mathrm{H} 9 \mathrm{c} 2$ cells. Firstly, the H9c2 cells were exposed to hypoxic conditions for $6,12,24$ and $36 \mathrm{~h}$, respectively, followed by $1 \mathrm{~h}$ of reoxygenation. HMGB1 expression was evaluated by RT-qPCR and western blot analysis at different time points. The mRNA expression of HMGB1 increased in a time-dependent manner (Fig. 1A). The protein expression of HMGB1 increased over time, although there was no significant difference in expression between 24 and $36 \mathrm{~h}$ (Fig. 1B and C). Accordingly, we selected $24 \mathrm{~h}$ as the time point for use in subsequent experiments. Additionally, we detected the expression of the miR-106b 25 cluster that is associated with EMT. As shown in Fig. 1D,the downregulation of miR-25 and miR-93 was observed in the H/R-exposed H9c2 cells over time. Howerer, there were no significant changes in the expression of miR-106b.

In order to examine the apoptosis of $\mathrm{H} / \mathrm{R}$-exposed cells, flow cytometry and western blot analysis were performed, respectively. As shown in Fig. 1F, the apoptosis rate was significantly upregulated following exposure to $\mathrm{H} / \mathrm{R}(\mathrm{P}<0.01)$. The protein expression of $\mathrm{Bcl}-2$, which inhibits cell apoptosis, was downregulated $(\mathrm{P}<0.05)$, and cleaved caspase-3 expression was significantly upregulated in the $\mathrm{H} / \mathrm{R}$-exposed cells $(\mathrm{P}<0.05)$ (Fig. $2 \mathrm{~A})$. Additionally, cell cycle analysis by flow cytometry revealed that the number of cells in the G1 phase significantly increased following exposure to $H / R(P<0.05)$, whereas the number of cells in the $\mathrm{S}$ phase decreased $(\mathrm{P}<0.05)$ (Fig. 1E). This indicated that the H/R-induced apoptosis of H9c2 cells may involve blocking of the cell cycle in the G1 phase. Finally, we evaluated the expression of fibrosis-related proteins using western blot analysis (Fig. 2B). The protein expression of fibronectin $(\mathrm{P}<0.05)$, TIMP2 $(\mathrm{P}<0.05)$, MMP2 $(\mathrm{P}<0.01)$, collagen I $(\mathrm{P}<0.01)$ and collagen III $(\mathrm{P}<0.01)$ were all significantly increased following exposure to $H / R$ compared with that in the control groups.

Collectively, these findings demonstrate that the $\mathrm{H} / \mathrm{R}$-exposed cells showed increased levels of apoptosis and fibrosis, upregulation of HMGB1 expression, downregulation of miR-25 expression and blocking of the cell cycle in the G1 phase.

Overexpression of miR-25 reverses the $H / R$-induced fibrosis and apoptosis of $H 9 c 2$ cells. To examine the effects of miR-25, we used a gain-of-function approach based on stable lentiviral transfection. The expression of miR-25 was significantly upregulated in the Lv-miR-25 group compared with the Con group $(\mathrm{P}<0.05)$, and it was downregulated in the Lv-anti-miR-25 group $(\mathrm{P}<0.05)$. There were no changes in miR-25 expression in the Lv-Con and Lv-anti groups (Fig. 3A). The mRNA and protein expression of fibrosis-related proteins was evaluated by RT-qPCR and western blot analysis, respectively, in gain-of and lost-of-function models of miR-25 cell lines subjected to H/R. As shown in Fig. 3B, the overexpression of miR-25 significantly reversed the H/R-induced expression of fibronectin $(\mathrm{P}<0.01)$, collagen I $(\mathrm{P}<0.01)$, collagen III $(\mathrm{P}<0.01)$, MMP2 $(\mathrm{P}<0.01)$ and TIMP2 $(\mathrm{P}<0.01)$. The H/R-induced expression of fibronectin $(\mathrm{P}<0.01)$, collagen $\mathrm{I}(\mathrm{P}<0.05)$, collagen III $(\mathrm{P}<0.05)$, MMP2 $(\mathrm{P}<0.05)$ and TIMP2 $(\mathrm{P}<0.05)$ was further increased when the miR-25-silenced cells were subjected to $H / R$. These findings suggesed that the overexpression of miR-25 inhibited fibrosis, which was induced by $H / R$ in $\mathrm{H} 9 \mathrm{c} 2$ cells. The results of western blot analysis showed that miR-25 overexpression led to similar effects on the expression of fibrosis-related genes (Fig. 3C).

Additionally, we examined the cell cycle in H9c2 cells exhibiting stable overexpression and silencing of miR-25 following exposure to $H / R$. The overexpression of miR-25 led to a significant decrease in the number of cells in the G1 phase $(\mathrm{P}<0.05)$, whereas the number of cells in the $\mathrm{S}$ phase was increased in miR-25-overexpressing cells exposed to $H / R$ $(\mathrm{P}<0.05)$ compared with the group of $\mathrm{H} 9 \mathrm{c} 2$ cells exposed to $\mathrm{H} / \mathrm{R}$ only (Con). Silencing miR-25 expression in combination with $\mathrm{H} / \mathrm{R}$ resulted in increased numbers of cells in the G1 phase and decreased numbers of cells in the S phase (Fig. 4A). Furthermore, apoptosis was evaluated by flow cytometry and western blot analysis. Fig. 4B and $\mathrm{C}$ show that the apoptotic rate in miR-25-overexpressing cells exposed to $\mathrm{H} / \mathrm{R}$ was decreased compared with the control group (H9c2 cells exposed only to $\mathrm{H} / \mathrm{R})(\mathrm{P}<0.05)$. Reduced miR-25 expression with $\mathrm{H} / \mathrm{R}$ led to a significant increase in the apoptotic rate $(\mathrm{P}<0.01)$. The protein expression of $\mathrm{Bcl}-2$ was upregulated in miR-25-overexpressing cells exposed to $H / R(P<0.05)$, and cleaved caspase-3 expression was significantly downregulated $(\mathrm{P}<0.05)$ (Fig. 4D). This indicated that the overexpression of miR-25 inhibited the $\mathrm{H} / \mathrm{R}$-induced apoptosis of $\mathrm{H} 9 \mathrm{c} 2$ cells through regulation of the cell cycle. 


\section{A}

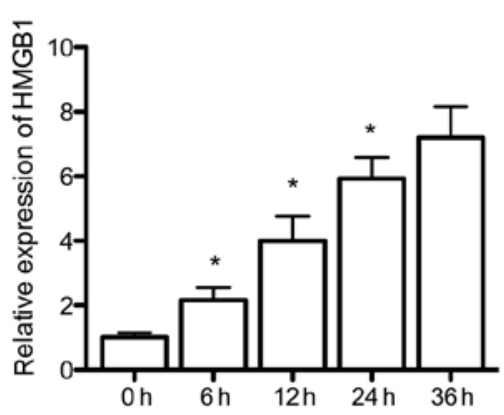

B

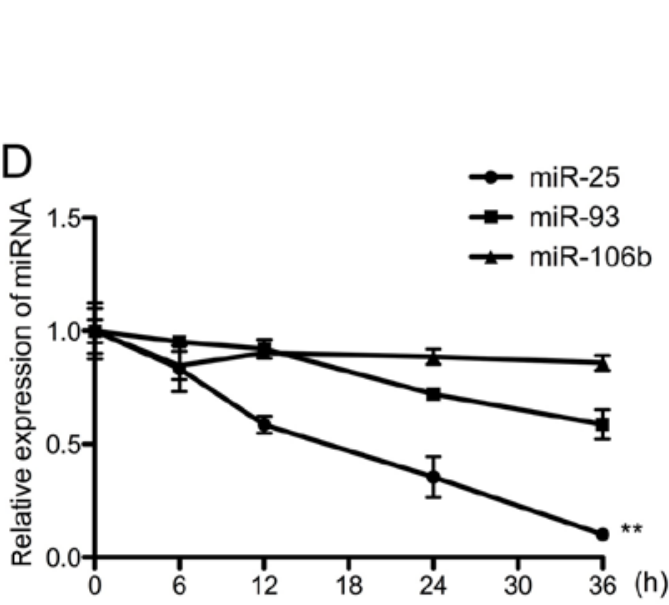

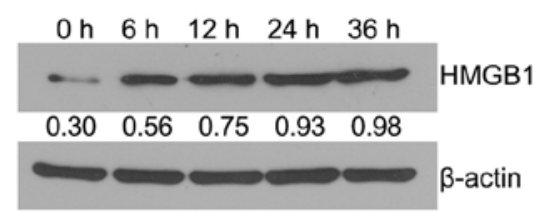

$\mathrm{E}$
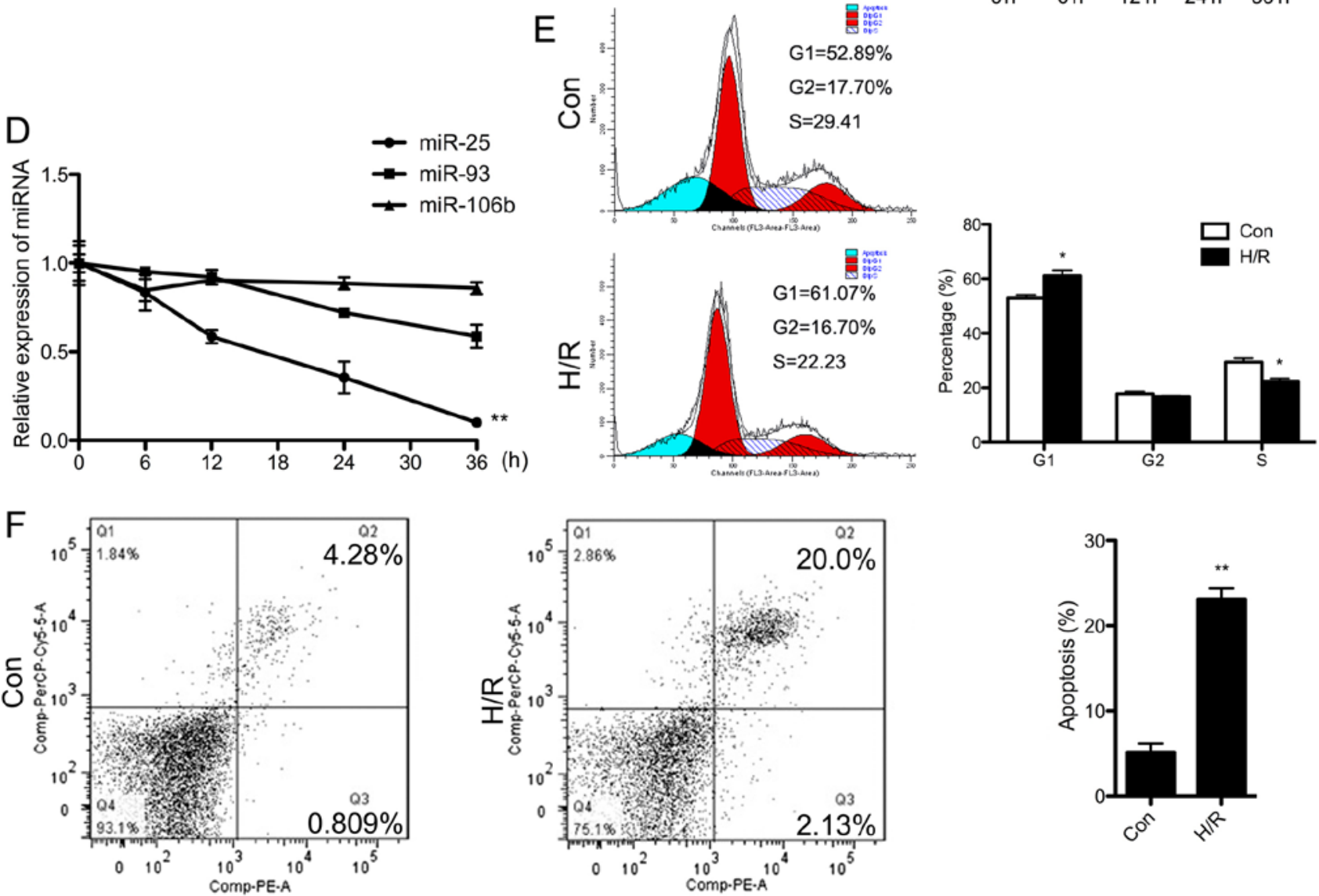

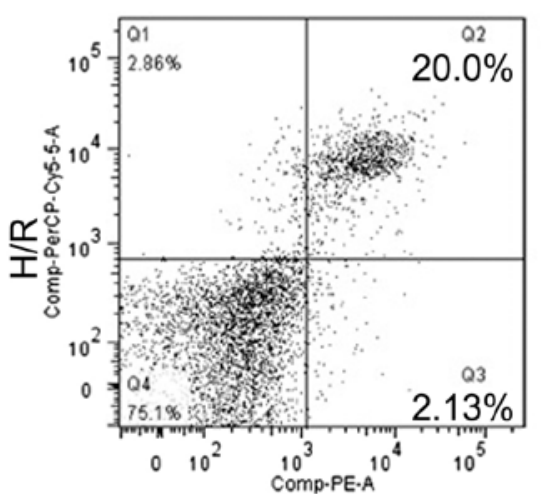

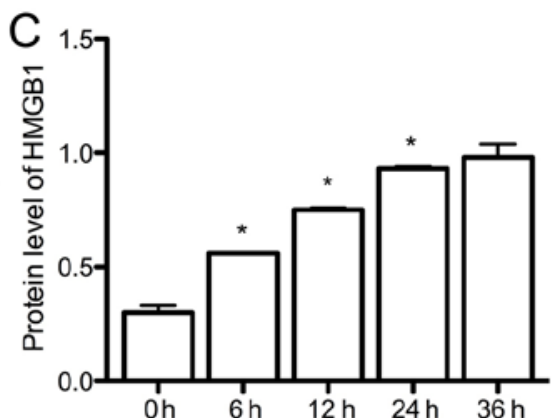

Figure 1. Fibrosis-inducing hypoxia/reoxygenation (H/R) exposure downregulates miR-25 expression and upregulates high-mobility group box 1 (HMGB1) expression in H9c2 cells. (A) The relative mRNA expression of HMGB1 in H9c2 cells exposed to H/R at different time points. (B) HMGB1 protein expression at different time points. (C) Quantification of (B) with densitometry. (D) The relative expression of the miR-106b 25 cluster in H/R-exposed cells detected by qPCR at different time points, including miR-93, miR-106b and miR-25. (E) Cell cycle analysis of the control (Con) and H/R groups evaulated by flow cytometry. Representative images are shown on the left, and the corresponding statistical result is shown on the right. (F) Flow cytometric analysis of cell apoptosis in H/R-exposed H9c2 cells. Representative cytometry plots are shown on the left, and the corresponding statistical result is shown on the right. Data are presented as the means $\pm \mathrm{SD}, \mathrm{n}=3$. ${ }^{*} \mathrm{P}<0.05$ and ${ }^{* *} \mathrm{P}<0.01$.

These findings demonstrated that the overexpression of miR-25 reversed the enhanced expression of fibrosis- and apoptosis-related genes induced by H/R.

miR-25directlytargets HMGB1 andinhibits HMGB1 expression in $H 9 c 2$ cells. The bioinformatics tool, microRNA.org-Targets and Expression, was used to predict the target genes for miR-25. HMGB1 was found to be a potential candidate target of miR-25. In order to confirm whether HMGB1 was indeed functionally targeted by miR-25, a dual-luciferase reporter gene assay was performed. Fig. 5A shows that the overexpression of miR-25 inhibited luciferase activity in the construct with the HMGB1-3'-UTR segment in H9c2 cells $(\mathrm{P}<0.05)$.
There was no change in luciferase reporter activity when the cells were transfected with the miR-25-inhibitor or negative controls. This demonstrated that HMGB1 was directly targeted by miR-25 in H9c2 cells. In addition, we performed western blot analysis in miR-25-overexpressing H9c2 cells (Fig. 5B). As shown in Fig. 5C, the overexpression of miR-25 suppressed the protein expression of HMGB1 compared with the control $(\mathrm{P}<0.01)$, and silencing miR-25 upregulated the expression of HMGB1 $(\mathrm{P}<0.05)$, with no changes observed in the pre-Con and anti-Con groups. Furthermore, the results of RT-qPCR showed similar effects of miR-25 on the mRNA expression of HMGB1 $(\mathrm{P}<0.05)$ (Fig. 5D). This indicated that HMGB1 was directly targeted and inhibited by miR-25. 
A
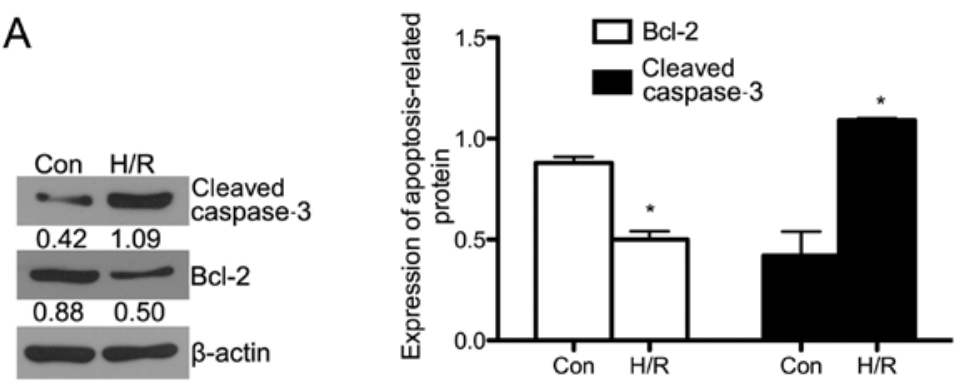

B
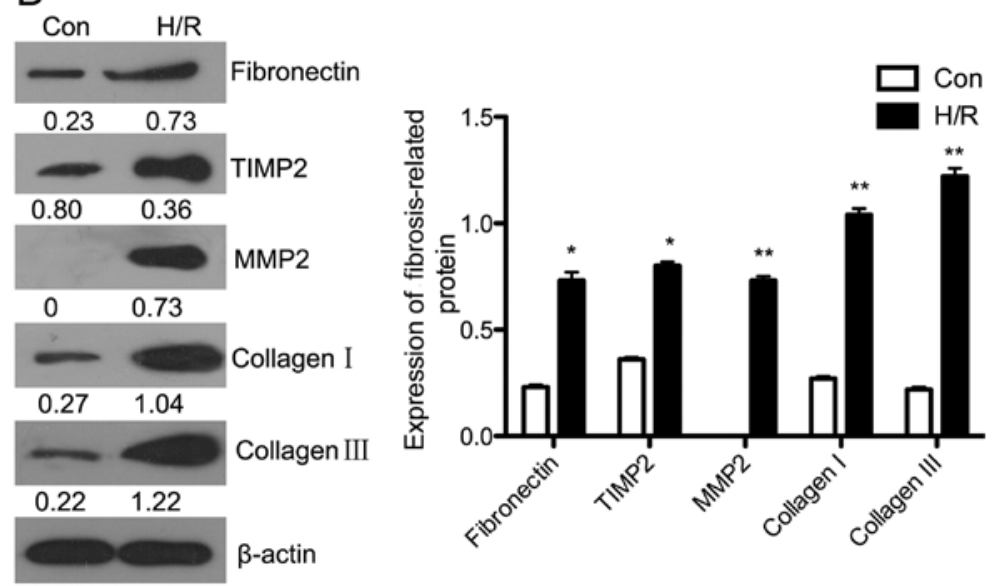

Figure 2. Hypoxia/reoxygenation (H/R) exposure affects the expression of both fibrosis- and apoptosis-related proteins in H9c2 cells. (A) Western blot analysis of the protein expression of cleaved caspase-3 and Bcl-2 in H/R-exposed H9c2 cells. (B) Western blot analysis was performed to evaluate the expression of fibrosis-related proteins, namely fibronectin, collagen I, collagen III, MMP2 and TIMP2. Data are presented as the means \pm SD, $n=3$. ${ }^{*}<0.05$ and ${ }^{* *} \mathrm{P}<0.01$.

A

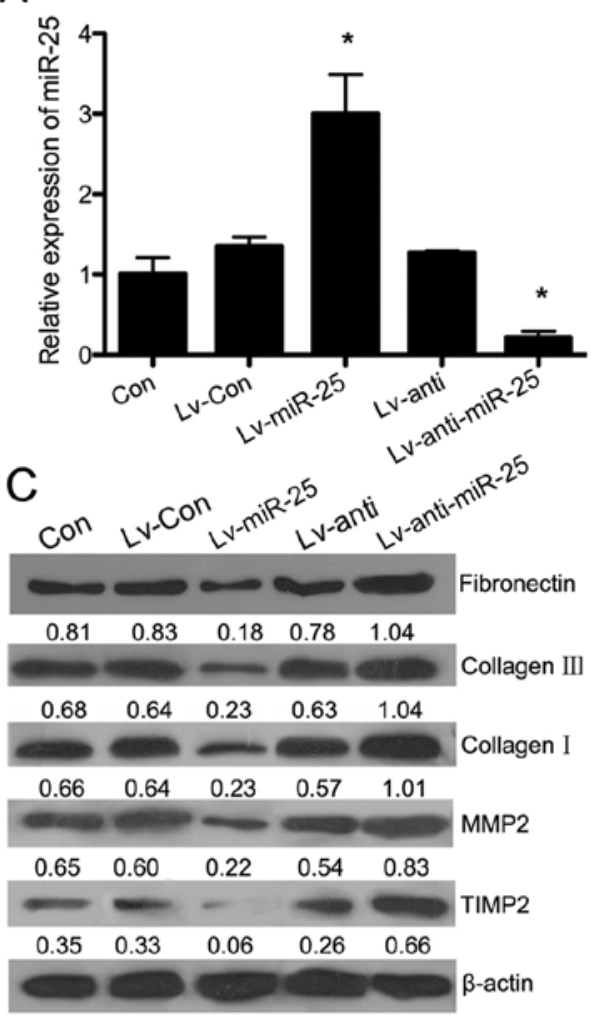

B

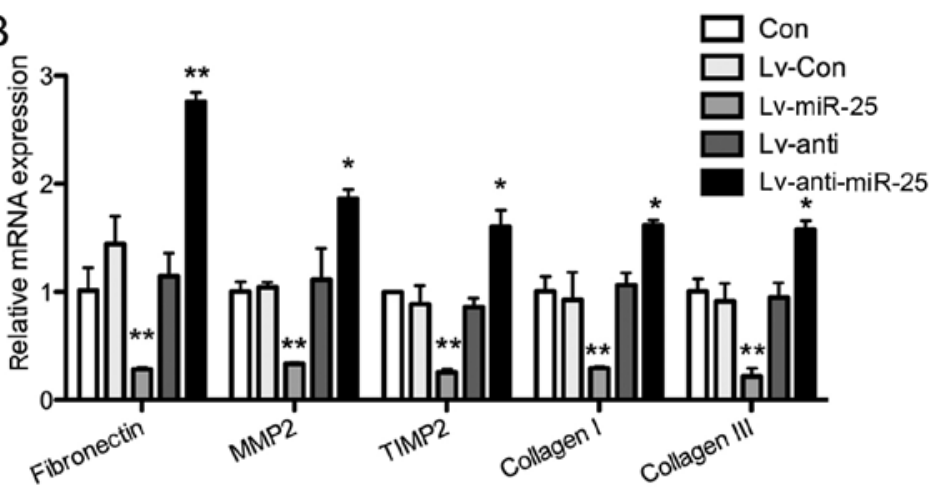

Figure 3. Overexpression of miR-25 downregulates the expression of fibrosis-related genes. (A) The relative expression of miR-25 detected by qPCR in H9c2 cells exhibiting stable overexpression and silencing of miR-25. (B) qPCR was used to analyze the relative expression of fibrosis-related genes (fibronectin, collagen I, collagen III, MMP2 and TIMP2) in hypoxia/reoxygenation (H/R)-exposed H9c2 stable cells lines. (C) Protein expression of fibrosis-related genes. Data are presented as the means $\pm \mathrm{SD}, \mathrm{n}=3$. ${ }^{*} \mathrm{P}<0.05$ and ${ }^{* *} \mathrm{P}<0.01$. 
A

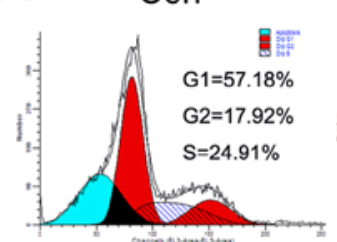

Lv-miR-25

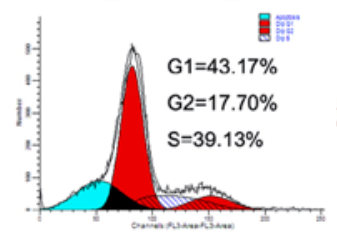

Lv-anti-miR-25
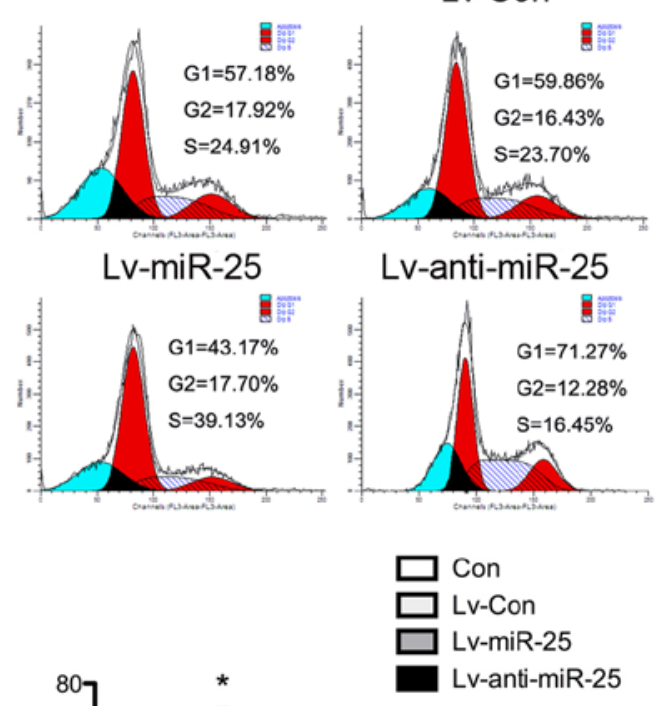

B

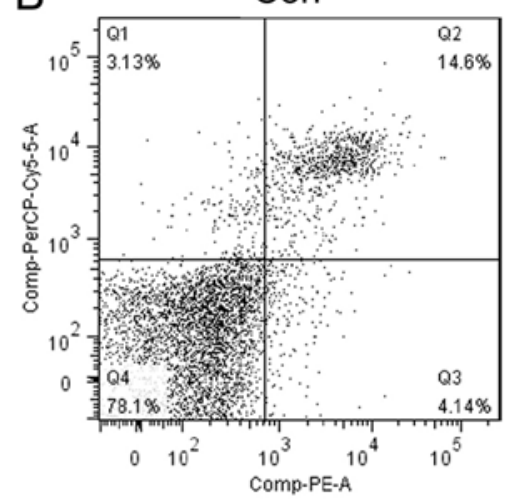

Lv-miR-25

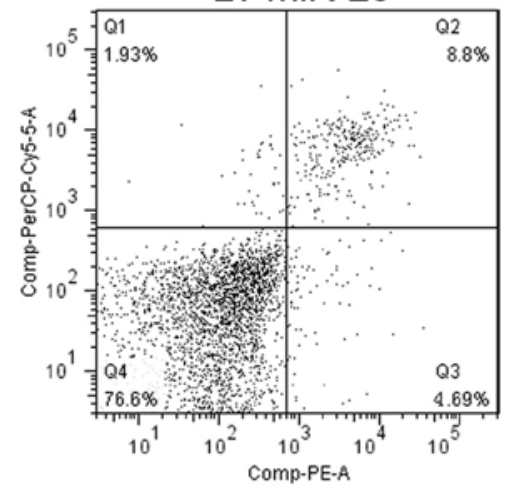

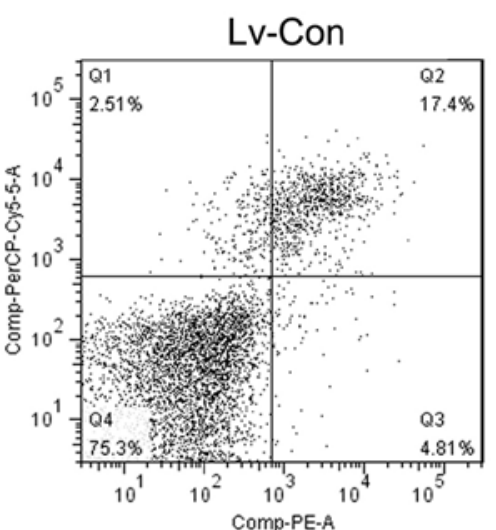
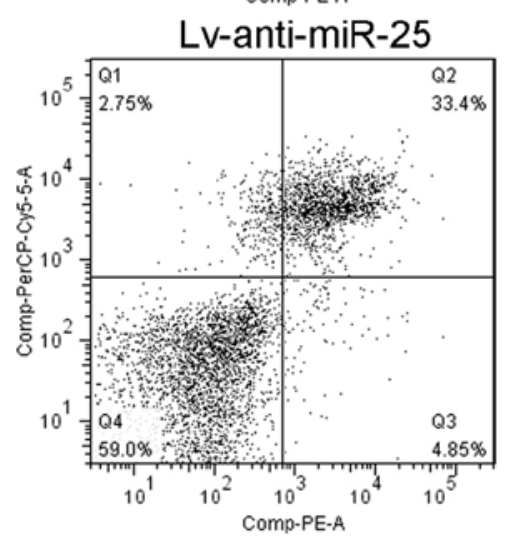

C

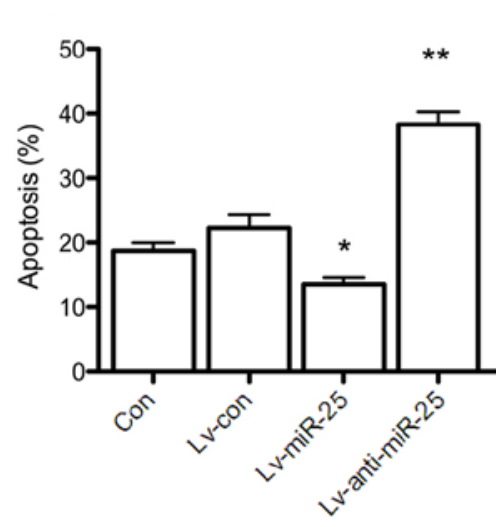

D

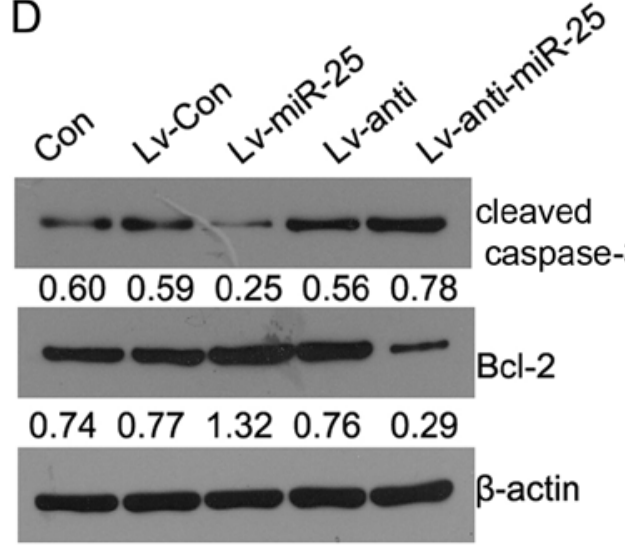

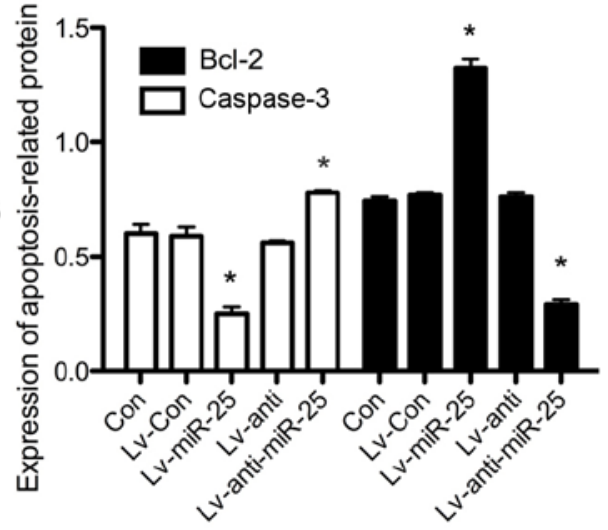

Figure 4. Overexpression of miR-25 suppresses the hypoxia/reoxygenation (H/R)-induced apoptosis of H9c2 cells. (A) Cell cycle analysis in H/R-exposed H9c2 stable cell lines exhibiting overexpression and silencing of miR-25. (B) Analysis of cell apoptosis by flow cytometry. (C) Percentages of viable and apoptotic cells. (D) Expression of apoptosis-related proteins (cleaved caspase-3 and Bcl-2) evaluated by western blot analysis. Data are presented as the means $\pm \mathrm{SD}, \mathrm{n}=3 .{ }^{*} \mathrm{P}<0.05$ and ${ }^{* *} \mathrm{P}<0.01$.

Downregulation of $H M G B 1$ reduces fibrosis via the TGF- $\beta 1 /$ Smad 3 pathway in H9c2 cells. To determine the effects of silencing HMGB1, HMGB1-shRNA or Ct-shRNA were transfected into H9c2 cells. As shown in Fig. 6A and B, the mRNA $(\mathrm{P}<0.001)$ and protein $(\mathrm{P}<0.001)$ expression of HMGB1 was significantly downregulated in the HMGB1-shRNA group.

To further examine the role of HMGB1 in fibrosis, HMGB1-shRNA or Ct-shRNA was transfected into H9c2 cells exposed to H/R. Then, the cells were analyzed by western blot analysis and RT-qPCR for the expression of fibrosis-related genes. The mRNA and protein expression levels of collagen $\mathrm{I}(\mathrm{P}<0.01)$, collagen III $(\mathrm{P}<0.01)$, MMP2 $(\mathrm{P}<0.05)$ and TIMP2 $(\mathrm{P}<0.01)$ were significantly decreased after silencing HMGB1 (Fig. 6C and D) in the H/R-exposed cells. This suggested that the downregulation of HMGB1 reduced the extent of fibrosis induced by $H / R$. Furthermore, the HMGB1-related signaling pathways were then evaluated by western blot analysis (Fig. 6E). The protein expression of TGF- $\beta 1(\mathrm{P}<0.05)$ and $\mathrm{p}-\mathrm{Smad} 3(\mathrm{P}<0.05)$ in the $\mathrm{H} / \mathrm{R}$-exposed cells was significantly downregulated following HMGB1 silencing, whereas no difference was observed in the expression of p-ERK1/2 after cell transfection. Taken together, these findings indicate that HMGB1 may enhance fibrosis through the TGF- $\beta 1 / \mathrm{Smad} 3$ signaling pathway in H9c2 cells exposed to $H / R$. 

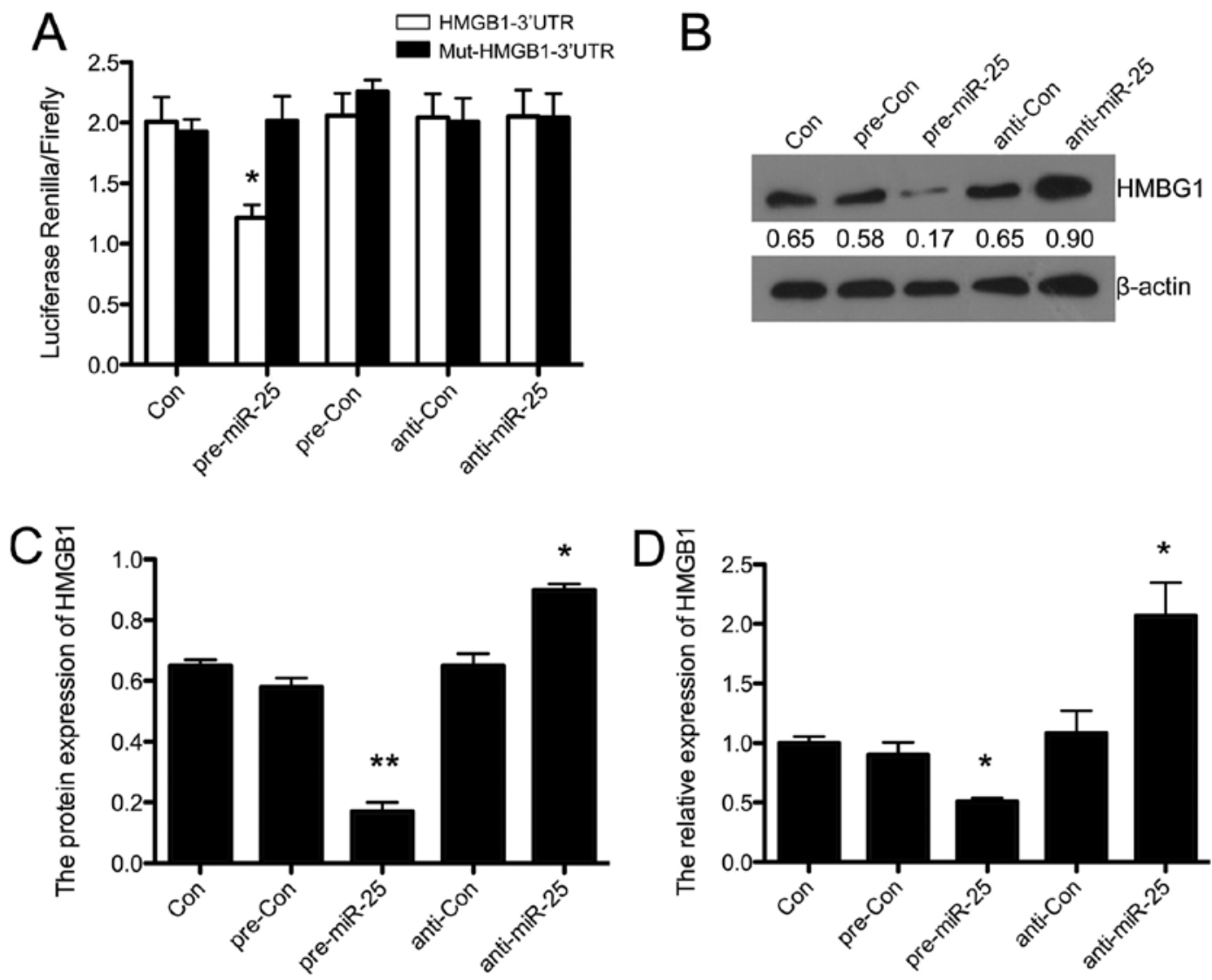

Figure 5. miR-25 directly targets high-mobility group box 1 (HMGB1) and induces its downregulation in H9c2 cells. (A) A Dual-luciferase reporter gene assay for targeting HMGB1. H9c2 cells were transfected with HMGB1-3'-UTR, combined with miR-25 or miR-25-inhibitor or the negative controls. Twenty-four hours after transfection, cells were lysed and the activity of both Renilla and firefly luciferase was assayed by the dual-luciferase reporter assay system. (B) Representative blot of HMGB1 expression measured by western blot analysis in hypoxia/reoxygenation (H/R)-exposed cells transfected with pre-miR-25 or anti-miR-25. (C) Statistical analysis of HMGB1 protein expression in H/R-exposed cells transfected with pre-miR-25 or anti-miR-25. (D) The relative mRNA expression of HMGB1 in H/R-exposed cells transfected with pre-miR-25 or anti-miR-25. Bars represent mean values $\pm \mathrm{SD}, \mathrm{n}=3$ for each group. ${ }^{*} \mathrm{P}<0.05$ and ${ }^{* * *} \mathrm{P}<0.01$.

An inhibitor of the TGF- $\beta 1 /$ Smad3 signaling pathway enhances the inhibitory effect of miR-25 on fibrosis in $\mathrm{H} 9 \mathrm{c} 2$ cells. A signaling pathway inhibitor of TGF- $\beta 1 / \mathrm{Smad} 3$, SB431542, was used in miR-25-overexpressing cells exposed to H/R. The expression of fibronectin, collagen I, collagen III, MMP2 and TIMP2 was evaluated by western blot analysis (Fig. 7A). The expression of all the fibrosis-related proteins in miR-25-overexpressing cells exposed to H/R was significantly suppressed by SB431542 ( $\mathrm{P}<0.05$ for fibronectin and TIMP2, $\mathrm{P}<0.01$ for MMP2, collagen I and collagen III). The protein expression of $\mathrm{Bcl}-2$ was upregulated after inhibitor treatment in the miR-25-overexpressing cells exposed to $\mathrm{H} / \mathrm{R}$ $(\mathrm{P}<0.01)$, and cleaved caspase-3 expression was significantly downregulated $(\mathrm{P}<0.05)$ (Fig. 7B). Fig. 7C shows that the apoptotic rate in inhibitor-treated cells exposed to $H / R$ was significantly lower $(\mathrm{P}<0.01)$. Collectively, the inhibitor of the TGF- $\beta 1 /$ Smad3 signaling pathway enhanced the inhibitory effect of miR-25-overexpression on fibrosis in H/R-exposed cells.

\section{Discussion}

Myocardial I/R injury often induces myocardial cell death and fibrosis (16), and miRNAs maybe involved in reducing the risk of myocardial apoptosis and fibrosis $(17,18)$. This study exam- ined the role of miR-25 in fibrosis as well as in the apoptosis of $\mathrm{H} 9 \mathrm{c} 2$ cells by observing miR-25 expression in H/R and by identifying the signaling pathway of apoptosis and fibrosis involving miR-25.

The expression of the miR-25 family of inflammation-associated miRNAs in the plasma of patients with unstable angina was downregulated in comparison with those who received no statins (19). The inhibition of miR-25 sensitized the murine myocardium to heart failure in a Hand2-dependent manner (20). miR-25 has also been proved to decrease collagen deposition (15). Moreover, we found that miR-25 was the most downregulated $\mathrm{miR}$ in the miR-25-106b family in $\mathrm{H} 9 \mathrm{c} 2$ cells following exposure to $\mathrm{H} / \mathrm{R}$. Exposure to $\mathrm{H} / \mathrm{R}$ induced the upregulation of fibrosis-related proteins, namely fibronectin, collagen I, collagen III, MMP2 and TIMP2, increased cell apoptosis and cell cycle blocking in the G1 phase. These effects indicate that the expression of miR-25 is associated with H/R-induced apoptosis and fibrosis. Moreover, in the miR-25-overexpressing cells exposed to H/R conditions, fibrosis was inhibited, cell apoptosis was prevented, and cell cycle blocking in the G1 phase was reversed. These results demonstrated that the overexpression of miR-25 inhibited H/R-induced apoptosis and fibrosis.

HMGB1, a chromatin-associated non-histone nuclear protein and extracellular damage-associated molecular 
A

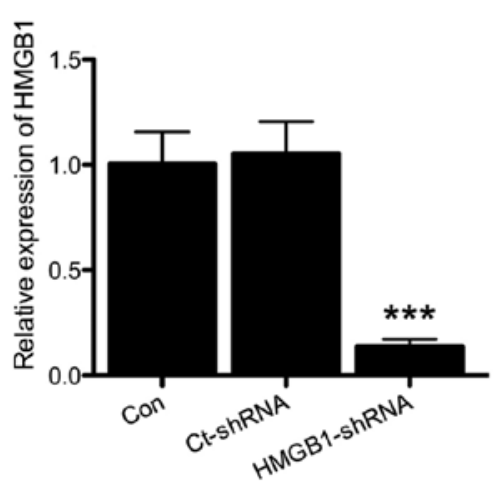

B

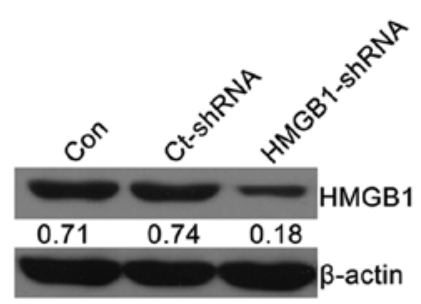

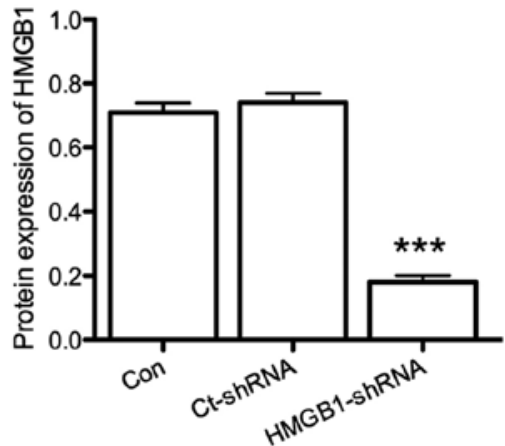

C
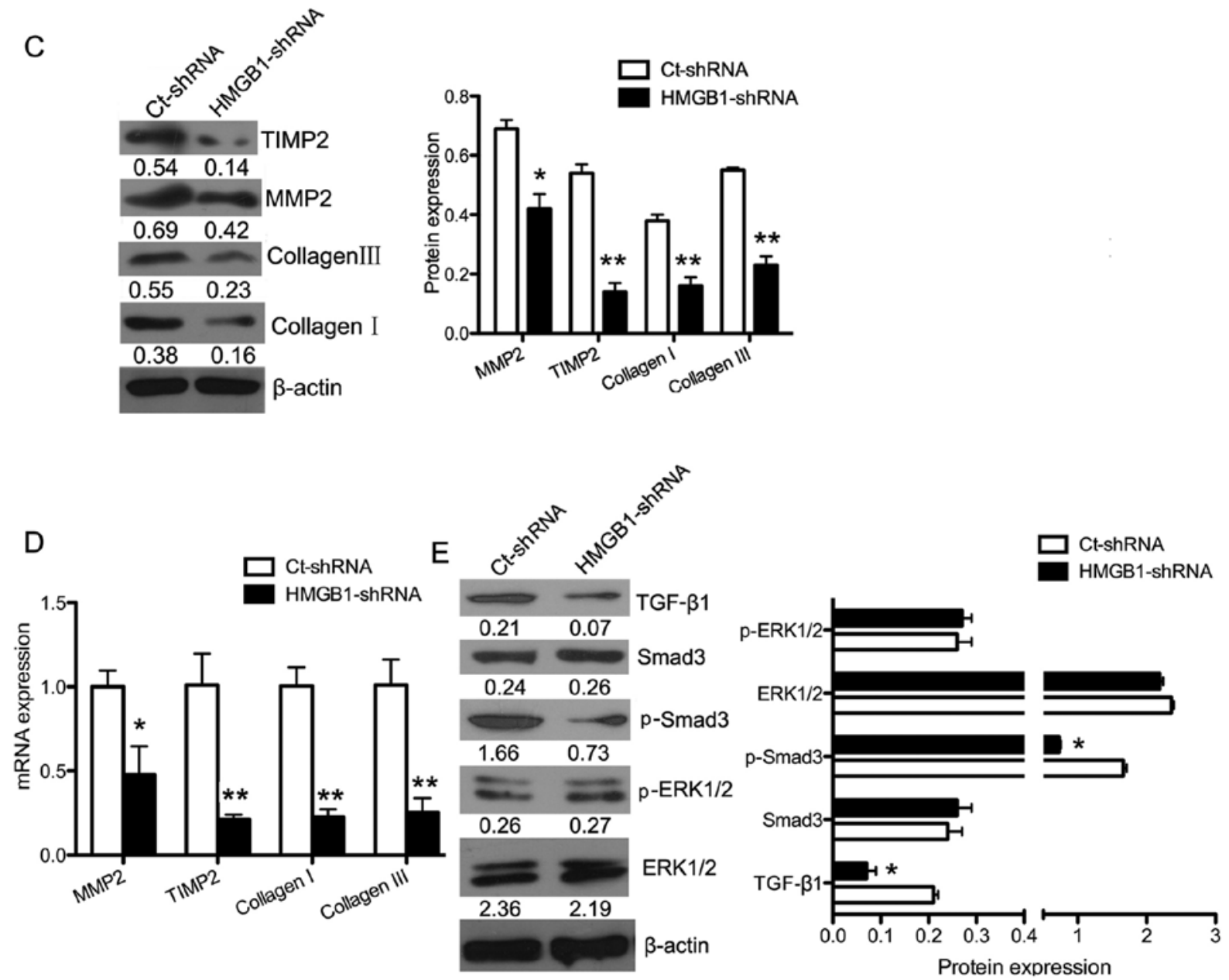

Figure 6. Downregulation of high-mobility group box 1 (HMGB1) reduces the expression of fibrosis-related proteins via the transforming growth factor- $\beta 1$ (TGF- $\beta 1$ )/Smad3 signaling pathway. (A) qPCR analysis of the mRNA expression of HMGB1 in H9c2 cells transfected with Ct-shRNA or HMGB1-shRNA. (B) Western blot analysis was performed to evaluate the expression of HMGB1 in H9c2 cells transfected with Ct-shRNA or HMGB1-shRNA. (C) The protein expression of fibrosis-related proteins measured by western blot analysis. (D) The relative mRNA expression of fibrosis-related genes (collagen I, collagen III, MMP2 and TIMP2) detected by qPCR in hypoxia/reoxygenation (H/R)-exposed cells transfected with Ct-shRNA or HMGB1-shRNA (E) Signaling pathway-related protein expression measured by western blot analysis. Bars represent the mean values $\pm \mathrm{SD}, \mathrm{n}=3$. ${ }^{*} \mathrm{P}<0.05,{ }^{* *} \mathrm{P}<0.01$ and ${ }^{* * *} \mathrm{P}<0.001$.

pattern (DAMP), is a critical regulator of cell death and survival (21). Accumulating evidence indicates that some non-immune cells, such as endothelial cells, hepatocytes (22) and cardiomyocytes (23) also actively secrete HMGB1. HMGB1 has been identified as a novel pro-inflammatory cytokine in several cardiovascular diseases (7,24-26). Additionally, HMGB1 has been found to function as an early pro-inflammatory mediator during myocardial I/R, and HMGB1 A box peptide (a specific HMGB1 antagonist) may protect against apoptosis and fibrosis induced by myocardial I/R injury $(27,28)$. These results suggested that HMGB1 plays an important role in $\mathrm{I} / \mathrm{R}$ injury, and is potentially a novel target for reducing $\mathrm{I} / \mathrm{R}$ injury. In our study, we found that HMGB1 was upregulated in the H9c2 cells following exposure to H/R. Simultaneously, the expression of miR-25 was downregulated. Moreover, we confirmed that HMGB1 may be a potential target of miR-25 using a bioinformatics tool. A dual-luciferase reporter gene assay confirmed that HMGB1 
A

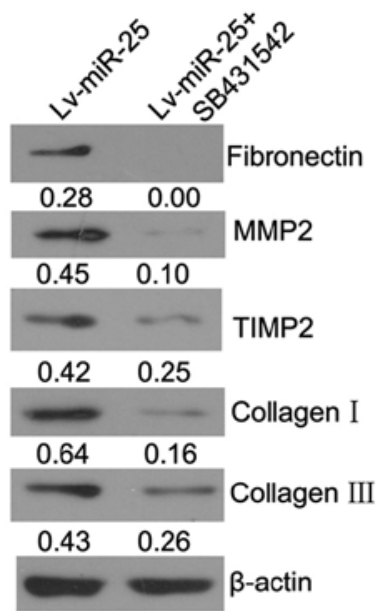

B
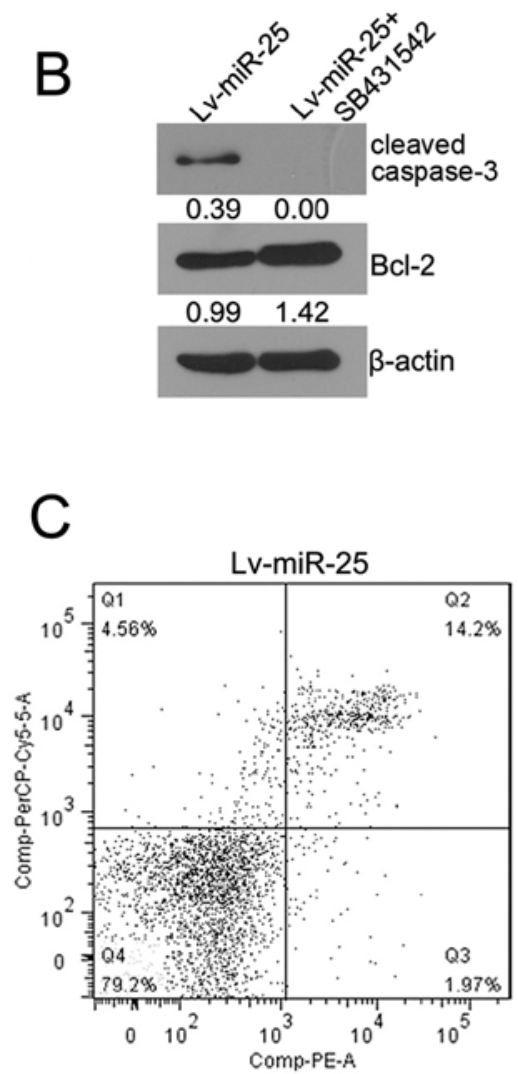
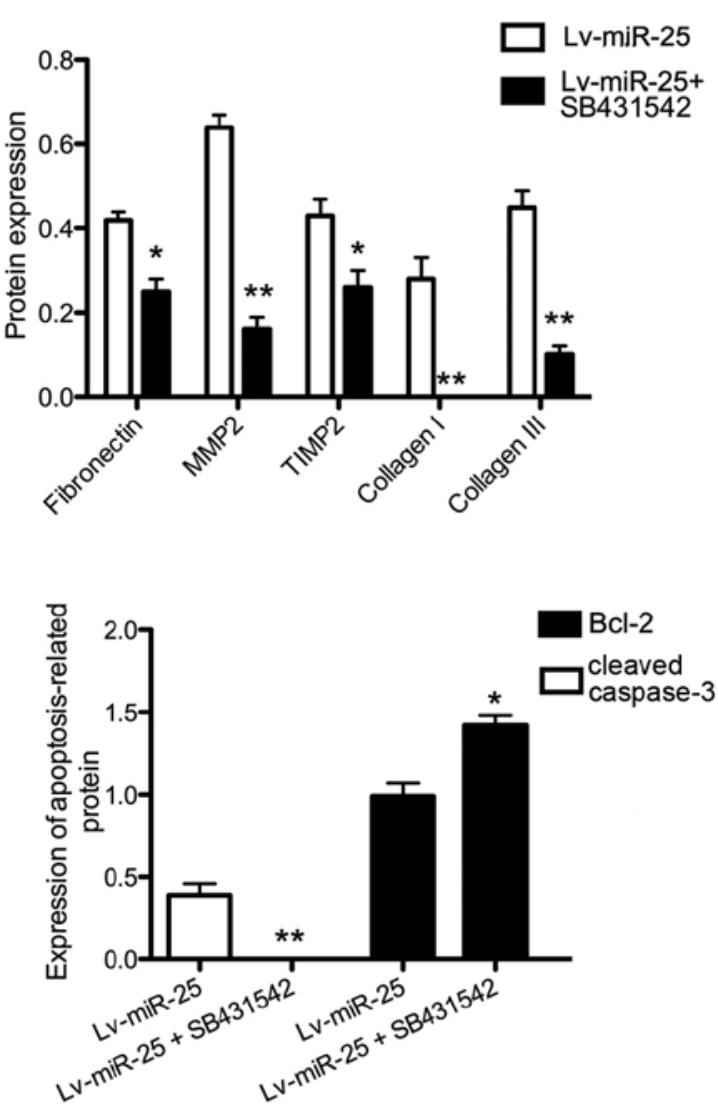

Figure 7. Transforming growth factor- $\beta 1$ (TGF- $\beta 1) / S m a d 3$ signaling pathway inhibitor enhances the protective effect of miR-25 against fibrosis and apoptosis. (A) Expression of fibrosis-related proteins (fibronectin, collagen I, collagen III, MMP2 and TIMP2) evaluated by western blot analysis in miR-25-overexpressing, hypoxia/reoxygenation (H/R)-exposed cells with or without TGF- $\beta 1 / \mathrm{Smad} 3$ inhibitor (SB431542). (B) Cell apoptosis-related protein expression (cleaved caspase- 3 and Bcl-2) was evaluated by western blot analysis. (C) Cell apoptosis analysis by flow cytometry. Data are presented as the means \pm SD, $\mathrm{n}=3 .{ }^{*} \mathrm{P}<0.05$ and ${ }^{* *} \mathrm{P}<0.01$.

was a direct target of miR-25. Additionally, the downregulation of miR-25 induced the upregulation of HMGB1. Thus, miR-25 inhibited the apoptosis and fibrosis induced by $H / R$ by targeting HMGB1.

Su et al demonstrated that HMGB1 induced cardiac collagen deposition through the PKC $\beta /$ ERK1/2 signaling pathway (29). Additionally, TGF- $\beta$ expression correlates with fibrous tissue deposition by inducing extracellular matrix protein synthesis following myocardial infarction (30). HMGB1 also prevents postinfarction adverse myocardial remodeling through the TGF- $\beta$ /Smad signaling pathway. It has been shown that the overexpression of the miR-106b-25 cluster in gastrointestinal cancer cells, and suggested that the miR-106b 25 cluster is a key modulator of TGF- $\beta$ signaling (31). Furthermore, Smad3 signaling was proved to play roles in modulating myocardial fibrosis, possibly through a pathway that entails the accumulation of miRNAs that decrease collagen gene expression (15). Therefore, we examined whether the PKC $\beta / E R K 1 / 2$ signaling pathway or the TGF- $\beta 1 / \mathrm{Smad} 3$ signaling pathway was involved in the regulatory effects of HMGB1 in fibrosis. We found that the downregulation of HMGB1 reduced fibrosis in the H/R-exposed H9c 2 cells through the TGF- $\beta 1 /$ Smad 3 pathway, rather than the 
PKC $\beta / E R K 1 / 2$ signaling pathway. Moreover, an inhibitor of the TGF- $\beta 1 /$ Smad3 signaling pathway (SB431542) enhanced the effect of miR-25.

In conclusion, the upregulation of miR-25 inhibited apoptosis and fibrosis in $\mathrm{H} / \mathrm{R}$-exposed cells by directly targeting HMGB1 through the TGF- $\beta 1 / \mathrm{Smad} 3$ pathway. These findings may provide novel insight into the pathogenesis of fibrosis, particularly with respect to H/R-related heart failure.

\section{References}

1. Lee SW, Won JY, Kim WJ, Lee J, Kim KH, Youn SW, Kim JY, Lee EJ, Kim YJ, Kim KW and Kim HS: Snail as a potential target molecule in cardiac fibrosis: paracrine action of endothelial cells on fibroblasts through snail and CTGF axis. Mol Ther 21: 1767-1777, 2013

2. Dhooghe B, Noël S, Huaux F and Leal T: Lung inflammation in cystic fibrosis: pathogenesis and novel therapies. Clin Biochem 47: 539-546, 2014.

3. Srivastava SP, Koya D and Kanasaki K: MicroRNAs in kidney fibrosis and diabetic nephropathy: roles on EMT and EndMT. BioMed Res Int 2013: 125469, 2013.

4. López-Novoa JM and Nieto MA: Inflammation and EMT: an alliance towards organ fibrosis and cancer progression. EMBO Mol Med 1: 303-314, 2009.

5. Andersson U and Tracey KJ: HMGB1 is a therapeutic target for sterile inflammation and infection. Annual Rev Immunol 29: 139-162, 2011.

6. Lynch J, Nolan S, Slattery C, Feighery R, Ryan MP and McMorrow T: High-mobility group box protein 1: a novel mediator of inflammatory-induced renal epithelial-mesenchymal transition. Am J Nephrol 32: 590-602, 2010.

7. Andrassy M, Volz HC, Igwe JC, Funke B, Eichberger SN Kaya Z, Buss S, Autschbach F, Pleger ST, Lukic IK, et al: High-mobility group box-1 in ischemia-reperfusion injury of the heart. Circulation 117: 3216-3226, 2008.

8. Roush S and Slack FJ: The let-7 family of microRNAs. Trends Cell Biol 18: 505-516, 2008.

9. Zhao J, Tang N, Wu K, Dai W, Ye C, Shi J, Zhang J, Ning B, Zeng $\mathrm{X}$ and Lin Y: MiR-21 simultaneously regulates ERK1 signaling in HSC activation and hepatocyte EMT in hepatic fibrosis. PLoS One 9: e108005, 2014.

10. Brønnum H, Andersen DC, Schneider M, Sandberg MB, Eskildsen T, Nielsen SB, Kalluri R and Sheikh SP: miR-21 promotes fibrogenic epithelial-to-mesenchymal transition of epicardial mesothelial cells involving Programmed Cell Death 4 and Sprouty-1. PLoS One 8: e56280, 2013.

11. Yang Y, Huang JQ, Zhang X and Shen LF: MiR-129-2 functions as a tumor suppressor in glioma cells by targeting HMGB1 and is down-regulated by DNA methylation. Mol Cell Biochem 404: 229-239, 2015.

12. Lu F, Zhang J, Ji M, Li P, Du Y, Wang H, Zang S, Ma D, Sun X and Ji C: miR-181b increases drug sensitivity in acute myeloid leukemia via targeting HMGB1 and Mcl-1. Int J Oncol 45: 383-392, 2014

13. Li X, Wang S, Chen Y, Liu G and Yang X: miR-22 targets the 3'UTR of HMGB1 and inhibits the HMGB1-associated autophagy in osteosarcoma cells during chemotherapy. Tumour Biol 35: 6021-6028, 2014.

14. Tang Q, Zhong H, Xie F, Xie J, Chen H and Yao G: Expression of miR-106b-25 induced by salvianolic acid B inhibits epithelialto-mesenchymal transition in HK-2 cells. Eur J Pharmacol 741: 97-103, 2014.

15. Divakaran V, Adrogue J, Ishiyama M, Entman ML, Haudek S, Sivasubramanian N and Mann DL: Adaptive and maladptive effects of SMAD3 signaling in the adult heart after hemodynamic pressure overloading. Circ Heart Fail 2: 633-642, 2009.
16. Barallobre-Barreiro J, Didangelos A, Schoendube FA, Drozdov I, Yin X, Fernández-Caggiano M, Willeit P, Puntmann VO, Aldama-López G, Shah AM, et al: Proteomics analysis of cardiac extracellular matrix remodeling in a porcine model of ischemia/reperfusion injury. Circulation 125: 789-802, 2012.

17. Chen Z, Hu Z, Lu Z, Cai S, Gu X, Zhuang H, Ruan Z, Xia Z, Irwin MG, Feng D and Zhang L: Differential microRNA profiling in a cellular hypoxia reoxygenation model upon posthypoxic propofol treatment reveals alterations in autophagy signaling network. Oxid Med Cell Longev 2013: 378484, 2013.

18. Di Y, Lei Y, Yu F, Changfeng F, Song W and Xuming M: MicroRNA expression and function in cerebral ischemia reperfusion injury. J Mol Neurosci 53: 242-250, 2014.

19. Zhang J, Ren JY, Chen H and Han GP: Statins decrease expression of five inflammation-associated microRNAs in the plasma of patients with unstable angina. Beijing Da Xue Xue Bao 47: 761-768, 2015 (In Chinese).

20. Dirkx E, Gladka MM, Philippen LE, Armand AS, Kinet V, Leptidis S, El Azzouzi H, Salic K, Bourajjaj M, da Silva GJ, et al: Nfat and miR-25 cooperate to reactivate the transcription factor Hand2 in heart failure. Nat Cell Biol 15: 1282-1293, 2013.

21. Klune JR, Dhupar R, Cardinal J, Billiar TR and Tsung A: HMGB1: endogenous danger signaling. Mol Med 14: 476-484, 2008.

22. Tsung A, Klune JR, Zhang X, Jeyabalan G, Cao Z, Peng X, Stolz DB, Geller DA, Rosengart MR and Billiar TR: HMGB1 release induced by liver ischemia involves Toll-like receptor 4-dependent reactive oxygen species production and calcium-mediated signaling. J Exp Med 204: 2913-2923, 2007.

23. Xu H, Su Z, Wu J, Yang M, Penninger JM, Martin CM, Kvietys PR and Rui T: The alarmin cytokine, high mobility group box 1 , is produced by viable cardiomyocytes and mediates the lipopolysaccharide-induced myocardial dysfunction via a TLR4/phosphatidylinositol 3-kinase gamma pathway. J Immunol 184: 1492-1498, 2010.

24. Hu X, Jiang H, Bai Q, Zhou X, Xu C, Lu Z, Cui B and Wen H: Increased serum HMGB1 is related to the severity of coronary artery stenosis. Clin Chim Acta 406: 139-142, 2009.

25. Andrassy M, Volz HC, Riedle N, Gitsioudis G, Seidel C, Laohachewin D, Zankl AR, Kaya Z, Bierhaus A, Giannitsis E, et al: HMGB1 as a predictor of infarct transmurality and functional recovery in patients with myocardial infarction. $\mathbf{J}$ Intern Med 270: 245-253, 2011.

26. Zhao D, Wang Y and Xu Y: Decreased serum endogenous secretory receptor for advanced glycation endproducts and increased cleaved receptor for advanced glycation endproducts levels in patients with atrial fibrillation. Int J Cardiol 158: 471-472, 2012.

27. Frangogiannis NG, Smith CW and Entman ML: The inflammatory response in myocardial infarction. Cardiovasc Res 53: 31-47, 2002.

28. Hu X, Fu W and Jiang H: HMGB1: A potential therapeutic target for myocardial ischemia and reperfusion injury. Int J Cardiol 155: 489, 2012

29. Su Z, Yin J, Wang T, Sun Y, Ni P, Ma R, Zhu H, Zheng D, Shen H, $\mathrm{Xu} \mathrm{W}$ and $\mathrm{Xu} \mathrm{H}$ : Up-regulated HMGB1 in EAM directly led to collagen deposition by a PKC $\beta /$ Erk1/2-dependent pathway: cardiac fibroblast/myofibroblast may be another source of HMGB1. J Cell Mol Med 18: 1740-1751, 2014.

30. Saltis J, Agrotis A and Bobik A: Regulation and interactions of transforming growth factor-beta with cardiovascular cells: implications for development and disease. Clin Exp Pharmacol Physiol 23: 193-200, 1996.

31. Petrocca F, Vecchione A and Croce CM: Emerging role of miR-106b-25/miR-17-92 clusters in the control of transforming growth factor beta signaling. Cancer Res 68: 8191-8194, 2008. 